Article

\title{
Experimental and Statistical Analysis of Saw Mill Wood Waste Composite Properties for Practical Applications
}

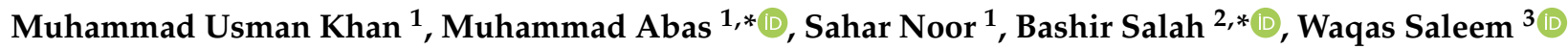 \\ and Razaullah Khan $4, *$ (D)
}

1 Department of Industrial Engineering, University of Engineering and Technology, Peshawar 25100, Pakistan; u.khan0007@yahoo.com (M.U.K.); sahar@uetpeshawar.edu.pk (S.N.)

2 Industrial Engineering Department, College of Engineering, King Saud University, P.O. Box 800, Riyadh 11421, Saudi Arabia

3 Department of Mechanical and Manufacturing Engineering, Institute of Technology, F91 YW50 Sligo, Ireland; saleem.waqas@itsligo.ie

4 Department of Engineering Management, University of Engineering and Applied Sciences, Swat, Mingora 19060, Pakistan

* Correspondence: muhammadabas@uetpeshawar.edu.pk (M.A.); bsalah@ksu.edu.sa (B.S.); razaullah@suet.edu.pk (R.K.)

check for updates

Citation: Khan, M.U.; Abas, M.; Noor, S.; Salah, B.; Saleem, W.; Khan, R. Experimental and Statistical Analysis of Saw Mill Wood Waste Composite Properties for Practical Applications. Polymers 2021, 13, 4038. https://doi.org/10.3390/ polym13224038

Academic Editor: Antonios N. Papadopoulos

Received: 15 October 2021

Accepted: 13 November 2021

Published: 22 November 2021

Publisher's Note: MDPI stays neutral with regard to jurisdictional claims in published maps and institutional affiliations.

Copyright: (C) 2021 by the authors Licensee MDPI, Basel, Switzerland. This article is an open access article distributed under the terms and conditions of the Creative Commons Attribution (CC BY) license (https:// creativecommons.org/licenses/by/ $4.0 /)$.

\begin{abstract}
The utilization of composite materials is increasing at a growing rate in almost all types of products, due to their strength-to-stiffness ratio. From this perspective, natural waste composites, i.e., wood waste composites, have also been investigated for their effective and sustainable employment. This paper deals with the application of hard and soft wood waste (i.e., acacia and cedar wood) with epoxy resin polymer to develop high strength and thermally stable wood composites. Mechanical (tensile, flexural, impact, and hardness) and thermal properties of samples are studied using Differential Scanning Calorimeter (DSC) and Thermo Gravimetric Analysis (TGA), respectively. The properties are evaluated by varying the type of wood waste and its percentage by weight. Based on the Taguchi Orthogonal Array Mixture Design, eighteen experiments are investigated. Analysis of variance (ANOVA) results show that wood waste type and wood waste content have a significant effect on all mechanical properties. From the TGA analysis, it is predicted that both types of wood waste composites exhibit similar thermal-induced degradation profiles in terms of the initial and final degradation temperatures. From the DSC results, higher glass transition temperature $\mathrm{T}_{\mathrm{g}}$ is detected in $10 \%$ of the hardwood waste composite, and a reducing tendency of glass transition temperature $\mathrm{T}_{\mathrm{g}}$ is observed with exceeding wood waste content. Moreover, hardwood waste at $10 \%$ demonstrated improved decomposition temperature $\mathrm{T}_{\mathrm{d}}$, due to strong adhesion between waste and matrix.
\end{abstract}

Keywords: wood waste; epoxy resin; differential scanning calorimeter; thermos gravimetric analysis; taguchi method; grey relational analysis

\section{Introduction}

The wood waste for consumable items is getting prime attention due to stringent environmental laws and waste management issues [1]. The recycling of wood waste can be increased by developing wood waste composite products [2,3]. Presently, wood processing industries have stepped into developing different types of wood waste composite products. However, the handling of wood waste needs precautionary measures, as the solid waste could be a form of poisonous dust that causes severe allergic reactions in certain conditions [4]. Besides some health concerns, potential use of wood waste is increasing in different industries, such as furniture items, boat making, pulp and paper manufacturing, construction, handicrafts, and some high-tech manufacturing industries.

It is important to investigate the specific epoxies and polymeric materials used for wood waste composites. For instance, the use of formaldehyde resin is detrimental to 
the environment, due to the emission of toxic gases during composite development processes [5]. The controlled usage of synthetic adhesive is decisive to eliminate the toxic and environmental impacts [6]. Other resins, such as soy-based resin and polyurethane resin, must be considered as an alternative to toxic resins in developing wood waste composites [7]. Among different types of resins, epoxy-resin is environmentally friendly and easier to process. Functionally, this resin exhibits excellent properties due to its high cross-linked characteristics, adequate strength, low cure shrinkage, increased fatigue and impact resistance, excellent thermal properties, chemical resistance, and dimensional stability [8]. The curing of epoxy-based composites is performed by adding aliphatic amines, anhydrides, and aromatics as hardeners $[9,10]$. These properties help in developing molds in the desired shapes. Curing cycles of epoxy-based composites specify the grade of cure of epoxy resin and significant influence on the mechanical properties of products. Epoxy/hardener ratios and ideal curing schedules are important to attain the desired properties of composite materials [11-16].

The research on polymer-based composites has opened new avenues for polymer formulations and developing new types of composites with specific properties of choice for specialized applications [17-19].The naturally occurring wood waste fibers added in composite materials include wood waste [12], white rice ash husk [13], pineapple leaf fiber [14], coconut shell waste, walnut hazelnut, and sunflower husk $[15,16]$. The utilization of wood waste fillers in polymers improves the mechanical characteristics, for example; the use of pinecone waste in high-density polyethylene (HDPE0 at different weights $(5 \%, 10 \%$, $15 \%$, and $20 \%$ ) substantially improves the mechanical strength [17]. In a reported study, a hybrid polymer composite-reinforced sal and teak wood flour was investigated by varying the concentration of reinforcements [18,19]. These studies explained the behavior of glass fiber reinforced epoxy composites by examining three factors; fiber weight percentage, the curing temperature, and epoxy hardener ratios. Some research studies have also used statistical techniques to evaluate the important parameters of epoxy-based wood waste composites, such as the Taguchi method [20,21]. In these studies, researchers employed statistical techniques to determine the load-dependent strain [22]. A few publications have highlighted wood waste composite testing techniques (such as tensile, flexural, etc.) for a particular application $[23,24]$. Some research studies elaborated the thermal behavior of natural wood fiber composites, their thermal decomposition, and flammability. The studies have shown that the existence of natural wood fibers creates an improved insulation effect, as compared to pure polymers matrices [25]. However, natural fibers consisting of lignin, cellulose, and hemicellulose, require increased processing temperature because of their cell wall enduring decomposition [26].

Differential scanning calorimetry (DSC) and thermogravimetric analyses (TGA) are thermal analysis techniques in the characterization of crystalline and amorphous pharmaceutical materials. The Thermogravimetric Analysis monitors the variations in the mass of a sample when the temperature is changed. Normally, the hearing is supplied at a constant rate over a specified time. Differential scanning calorimetry tracks the variations in the heat flow going in and coming out of the sample when there is a change in temperature under a controlled atmosphere. While performing this test, heating and cooling cycle are ensured in an inert atmosphere. TGA and DSC techniques are employed to investigate physical and chemical characteristics of composite samples [27]. A TGA curve shows the behavior of weight reduction during thermal evaporation or chemical reaction, while the DSC curve indicates exothermic and endothermic processes. These curves are used to establish $T_{g}$ and $T_{d}[28,29]$ temperatures of composite samples. The reported studies have shown that exothermic peaks are observed at $270{ }^{\circ} \mathrm{C}$ and $360{ }^{\circ} \mathrm{C}$, which were assigned to the decomposition of cellulose and hemicellulose [30]. Oliveira et al. [31] investigated the thermal properties of natural palm fibers from $20{ }^{\circ} \mathrm{C}$ to $200{ }^{\circ} \mathrm{C}$ under an inert gas atmosphere $\left(\mathrm{N}_{2}\right)$ with a heating rate of $10^{\circ} \mathrm{C} / \mathrm{min}$. Waseem et al. [32] investigated the tensile creep behavior of PLA material. Some researchers have explored the possibilities of 
using wood waste composites in high-tech applications, such as an insulation material for high temperature applications in aerospace and automobiles [33,34].

Based on the literature review, it is concluded that only limited studies are reported that deal with the utilization of hardwood and softwood waste epoxy resin composites. Moreover, this research would be novel in this perspective to investigate the mechanical and thermal stability of such composites. The authors have compiled all the reports and concluded that the available studies have covered only limited characteristics of some specific composites, for example, the usage of sundiwood waste in composite [17,35], thermal study of natural fibers composite [36], and flammability of natural fiber reinforced composite [37], etc. Considering this, the presented study focuses on hard and soft wood waste (i.e., acacia and cedar wood) reinforced with epoxy resin polymer to improve the mechanical strength and thermally stability. Mechanical and thermal tests performed on different samples include tensile, flexural, hardness, impact, differential scanning calorimeter (DSC), and thermo gravimetric analysis (TGA). Mechanical strength of samples is evaluated by varying wood waste type (at two-level i.e., acacia and cedar wood), and percentage waste weight (at three levels i.e., 10\%, 20\%, and 30\%). Based on Taguchi orthogonal array mixture design, eighteen experiments are analyzed. Analysis of variance (ANOVA) is performed to obtain the significant factors for tensile, flexural, hardness, and impact strength.

\section{Materials and Methods}

\subsection{Material}

The wood waste used in the present study is hard and soft wood, i.e., acacia and cedar. The waste of these types of wood is collected in the form of wood flour (fine powder) after sawmill machining from local manufacturing industries. The softwood and hardwood waste were filtered through 60 mesh stainless steel wire sieves that give approximately 250 microns particle size of powder. The filtered powder was then dried under the sun (with temperature variation of $35-37^{\circ} \mathrm{C}$ ) for $48 \mathrm{~h}$. The waste (fine powder) is shown in Figure 1.

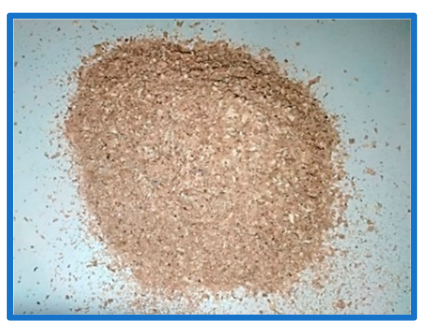

(a)

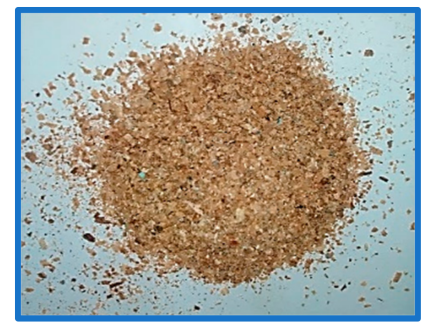

(b)

Figure 1. Wood waste (a) Acacia (b) Cedar.

Epikote 828 was used as epoxy resin. It is an unchanged liquid bisphenol-Aepichlorohydrin epoxide resin of medium viscosity. Epikote 828 is the standard liquid resin that is used in several applications. It provides an excellent resistance to filler settling and exhibits a great level of mechanical and chemical resistance in the final cure state. The properties of epoxy and hardener are summarized in Table 1. Figure 2a shows the structure of Epikote 828. The hardener (curing agent) used in this experimental work is HY 951 (Triethylenetetramine TETA), which is a liquid of low viscosity of an aliphatic amine. The chemical structure of HY 951 is shown in Figure 2b. 
Table 1. Properties of epoxy and hardener.

\begin{tabular}{|c|c|c|c|c|c|}
\hline \multicolumn{4}{|c|}{ Properties of Epoxy (Epikote 828) } & \multicolumn{2}{|c|}{ Properties of Hardener HY 951} \\
\hline Sr No. & Property & Test Method & Value + Unit & Property & Value in Units \\
\hline 1 & Epoxy Group Content & SMS 2062 & $5260-5420 \mathrm{mmol} / \mathrm{kg}$ & Molecular Weight & 146.24 \\
\hline 2 & Viscosity at $25^{\circ} \mathrm{C}$ & ASTM D445 & 9-14 Pas & Viscosity (Hoeppler) at $25^{\circ} \mathrm{C}$ & $450 \mathrm{mPas}$ \\
\hline 3 & Color & ASTM D1209 & 100 max Pt-Co & Specific Gravity at $25^{\circ} \mathrm{C}$ & $1.1-1.2 \mathrm{~g} / \mathrm{cm}^{3}$ \\
\hline 4 & Epoxy Equivalent Weight & & $182-194 \mathrm{~g}$ & Color & Pale Yellow or yellow Liquid \\
\hline 5 & Density at $25^{\circ} \mathrm{C}$ & SMS1374 & $1.16 \mathrm{Kg} / \mathrm{L}$ & Boiling Point & $284-287^{\circ} \mathrm{C}$ \\
\hline 6 & Flash Point (PMCC) & ASTM D93 & $>150{ }^{\circ} \mathrm{C}$ & & \\
\hline
\end{tabular}

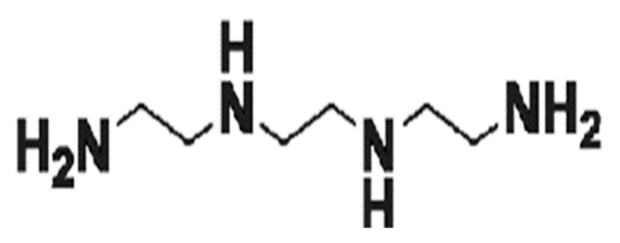

(a)

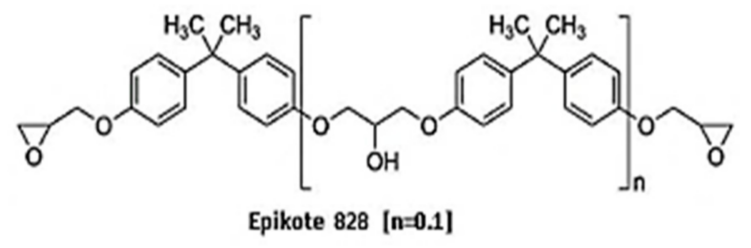

(b)

Figure 2. (a) Chemical Structure of Epikote 828 [38] (b) Chemical Structure of HY 951 [39].

\subsection{Sample Preparation and Responses Measurement}

For the composite preparation, first the epoxy and hardener were mixed in a ratio of 2:1, 5:2, and 3:1 by weight [40] and mechanically stirred for approximately $5 \mathrm{~min}$. Then the wood flour was mixed with solution in different weight percentages (i.e., 10\%, 20\%, and $30 \%$ ) and mechanically stirred continuously for approximately 5 to $8 \mathrm{~min}$ to constitute the uniform solution. Finally, the mixture was poured into a mold/chamber and cured for approximately $24 \mathrm{~h}$ at room temperature. Figure 3 shows the mold designed according to ASTM standard mold for hardness and impact test.

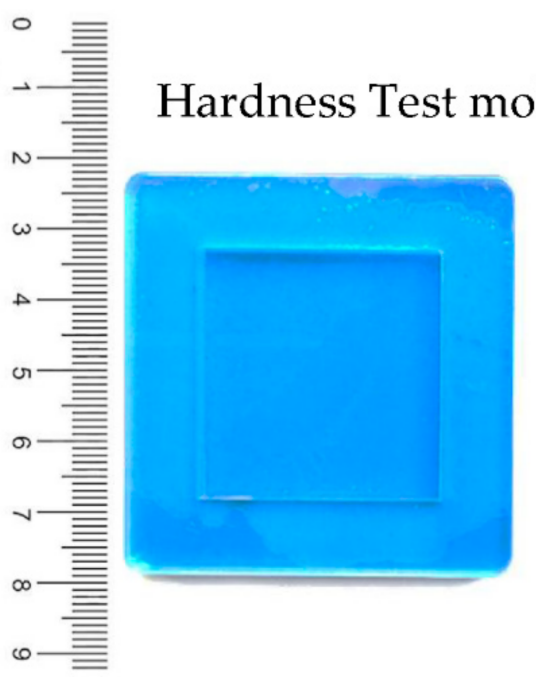

\section{Impact Test mold}

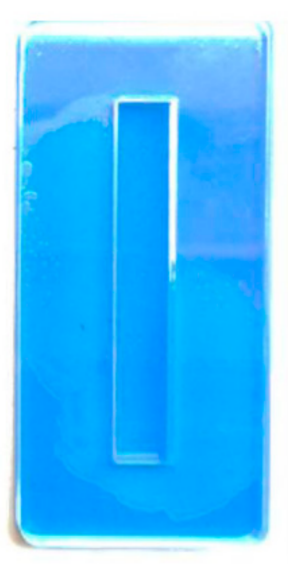

Figure 3. Molds for hardness and impact test, according to standard ASTM standards.

\subsection{Mechanical Testing}

Mechanical tests, such as tensile, bending (flexural), impact, and hardness are performed to evaluate the mechanical properties of samples. Tensile, flexural, impact, and hardness tests were performed according to ASTM D638 type I standard at $2 \mathrm{~mm} / \mathrm{min}$, ASTM D790 at $1 \mathrm{~mm} / \mathrm{min}$, ASTM D4812, and ASTM D735, respectively, as shown in Figure 4. 
Tensile Test Specimen based on Soft Wood

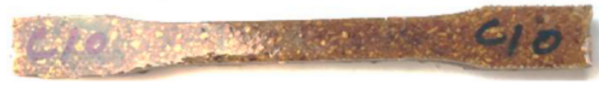

(a)

Tensile Tesile Specimen based on Hard Wood

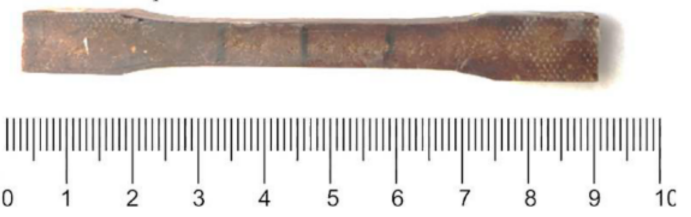

Hardness Test Specimen based on Soft Wood

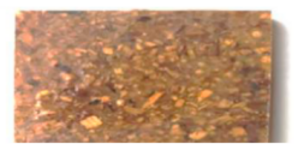

Hardness Test Specimen based on Hard

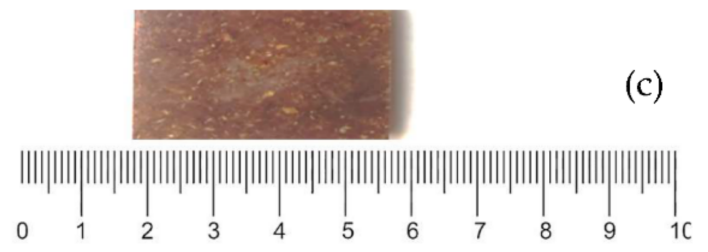

Flexural Test Specimen based on Soft Wood Powder

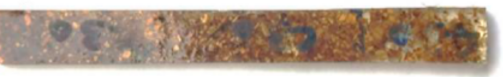

Flexural Test Specimen based on Hard Wood Powder

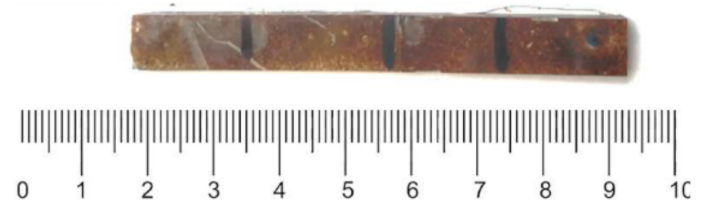

Impact Test Specimen based on Soft Wood Powder

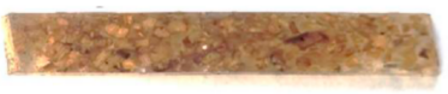

Impact Test Specimen based on Hard Wood Powder
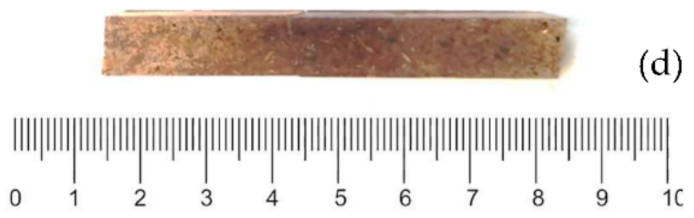

Figure 4. Mechanical tests (a) tensile test (b) flexural test (c) impact test (d) hardness test.

\subsection{Thermal Tests}

Thermal properties are studied with Differential scanning Calorimetry (DSC) and Thermogravimetric Analysis (TGA). DSC is widely used as an experimental tool for a thermal investigation that detects heat flow from a specimen. Tests are performed according to a ASTM D3418-15 standard. A sample of the epoxy composite weighing approximately 3 to 10 milligrams is placed inside an aluminum hermetic pan and the aluminum capsule is sealed by means of a sample press. Finally, it is placed in a DSC machine. The heating rate at $20{ }^{\circ} \mathrm{C} / \mathrm{min}$ is maintained to determine the conversion profile and total heat released during the dynamic curing process. The range of heat supply is monitored from room temperature to $600{ }^{\circ} \mathrm{C}$. The data extracted are used to determine the glass transition temperature, crystallization temperature, and decomposition temperature.

The TGA is performed to study the thermal stability of a sample material as a function of its temperature. The samples were prepared according to ASTM E1131 under an inert gas atmosphere (nitrogen), and then heated slowly at a rate of $20{ }^{\circ} \mathrm{C} / \mathrm{min}$. TGA measures the change in weight of specimen material with respect to its function of time and function of temperature. Generally, the range of temperature is set rendering to the temperature.

\subsection{Design of Experiments}

The experiment design is an important monitoring tool for both modeling and analyzing the impact of control factors. The most important step in the experiment design is the selection of control factors and their levels. Thus, in the presented study, levels were set based on the literature review. The selected levels are shown in Table 2. Experimental runs are designed considering Taguchi L18 orthogonal array mixture design, as tabulated in Table 3. The basic purpose, in order to select the Taguchi method, is to minimize the number of experiments and cost of experimentation [41]. 
Table 2. Input factors and their levels.

\begin{tabular}{|c|c|c|c|c|}
\hline Factors & Symbols & & Levels & \\
\hline Continuous Factor & & 1 & 2 & 3 \\
\hline Wood waste weight in percentage (WWP) & A & $10 \%$ & $20 \%$ & $30 \%$ \\
\hline Weight percent ratio of epoxy and hardener (WPE) & $\mathrm{B}$ & $2.00=2: 1$ & $2.50=5: 2$ & $3.0=3: 1$ \\
\hline Wood waste type (WWT) & $\mathrm{C}$ & Softwood waste & Hardwood waste & \\
\hline
\end{tabular}

Table 3. Taguchi orthogonal array design $\left(\mathrm{L}_{18}\right)$ and measured responses.

\begin{tabular}{|c|c|c|c|c|c|c|c|}
\hline \multirow{2}{*}{ No. of Experiments } & \multicolumn{3}{|c|}{ Factors } & \multicolumn{4}{|c|}{ Responses } \\
\hline & $\mathbf{A}$ & B & $\mathrm{C}$ & Tensile Strength (MPa) & Flexural Strength (MPa) & Impact Strength $\left(\mathrm{J} / \mathrm{m}^{2}\right)$ & Hardness (HV) \\
\hline 1 & 1 & 1 & 1 & 16.393 & 44.167 & 8.20 & 14.72 \\
\hline 2 & 1 & 1 & 2 & 23.793 & 61.389 & 16.82 & 21.54 \\
\hline 3 & 1 & 2 & 1 & 17.200 & 46.111 & 8.80 & 15.63 \\
\hline 4 & 1 & 2 & 2 & 24.367 & 68.056 & 17.43 & 21.89 \\
\hline 5 & 1 & 3 & 1 & 14.220 & 41.389 & 7.20 & 13.02 \\
\hline 6 & 1 & 3 & 2 & 23.767 & 67.500 & 16.70 & 21.23 \\
\hline 7 & 2 & 1 & 1 & 14.453 & 42.222 & 6.20 & 13.45 \\
\hline 8 & 2 & 1 & 2 & 21.247 & 63.056 & 13.65 & 18.56 \\
\hline 9 & 2 & 2 & 1 & 14.433 & 40.833 & 6.17 & 13.41 \\
\hline 10 & 2 & 2 & 2 & 21.693 & 72.222 & 14.36 & 20.78 \\
\hline 11 & 2 & 3 & 1 & 14.320 & 36.944 & 6.30 & 13.23 \\
\hline 12 & 2 & 3 & 2 & 21.167 & 70.556 & 13.30 & 18.12 \\
\hline 13 & 3 & 1 & 1 & 12.420 & 35.278 & 5.50 & 11.88 \\
\hline 14 & 3 & 1 & 2 & 16.767 & 51.944 & 10.59 & 15.16 \\
\hline 15 & 3 & 2 & 1 & 13.073 & 28.056 & 5.87 & 12.98 \\
\hline 16 & 3 & 2 & 2 & 18.460 & 63.611 & 11.45 & 16.65 \\
\hline 17 & 3 & 3 & 1 & 11.220 & 29.167 & 4.80 & 11.05 \\
\hline 18 & 3 & 3 & 2 & 22.067 & 66.389 & 13.55 & 19.45 \\
\hline
\end{tabular}

\subsection{Single and Multi-Response Optimization}

Figure 5 shows the methodology deployed for single- and multi-response optimization based on the Taguchi signal to Noise (S/N) ratios and Grey relational analysis (GRA).

Single responses are optimized based on Taguchi S/N ratios. The Taguchi-based S/N ratios determined the variation in the quality characteristics of responses from desired values [42]. In the present study, the objective function is to maximize the responses, such as tensile strength, flexural strength, impact, and hardness. The better-quality characteristics $(\mathrm{S} / \mathrm{N}$ ratios) are measured using Equation (1):

$$
\eta=-10 \log \left(\frac{1}{n} \sum_{j=1}^{n} \frac{1}{y_{j}^{2}}\right)
$$

where, $\eta=\mathrm{SN}$ ratio in $\mathrm{db}, y_{j}=$ Experimentally observed values (jth experiment), $n=$ no of experiment.

For multi-response optimization, GRA is deployed. The steps followed for GRA are:

Step 1: Normalization

The multiple responses are normalized between the range of zero and 1 by applying the formula to ignore the effect of implementing different units and to reduce the variability. The normalized equation corresponding to the higher the better can be evaluated as:

$$
\mathrm{P}_{\mathrm{i}}(\mathrm{j})=\frac{x i(j)-\min x i(j)}{\max x i(j)-\min x i(j)}
$$

Step 2: Calculate Deviation Sequence

By applying the normalized value of responses, Equation (3) gives the deviation sequence for a given reference and comparability sequence.

$$
€_{0 \mathrm{i}}=|| Y_{0}(j)-Y_{i}(j)||
$$


where $€_{0}=$ deviation sequence, $\mathrm{Y}_{0}(\mathrm{k})=$ max value, $\mathrm{Y}_{\mathrm{i}}(\mathrm{k})=$ current value

Step 3: Calculate the Grey Relational Coefficient GRC:

The GRC [43] is calculated to direct the relationship between the ideal (finest) and actual normalized experimental results. This can be expressed in the form of Equation (4):

$$
\xi_{\mathrm{i}}=\frac{€ \min +\xi € \max }{€_{0 \mathrm{i}}(\mathrm{j})+€ \max \xi}
$$

where $€_{0 \mathrm{i}}=$ deviation sequence

Step 4: Apply Grey Relational Grade GRG:

The use of GRG [44] is considered by taking an average of GRC corresponding to each experiment. The basis of overall responses of the multiple performances characteristics is the GRG, which is considered as the prime function. Thus, optimization of complex multipurpose characteristics is changed to a single GRG. Equation of GRG can be obtained as:

$$
\beta_{\mathrm{i}}=\frac{1}{n} \sum_{j=1}^{n} \xi \mathrm{i}(j)
$$

where $\beta_{i}=$ GRG for experiments, $n=$ no of performance characteristics.

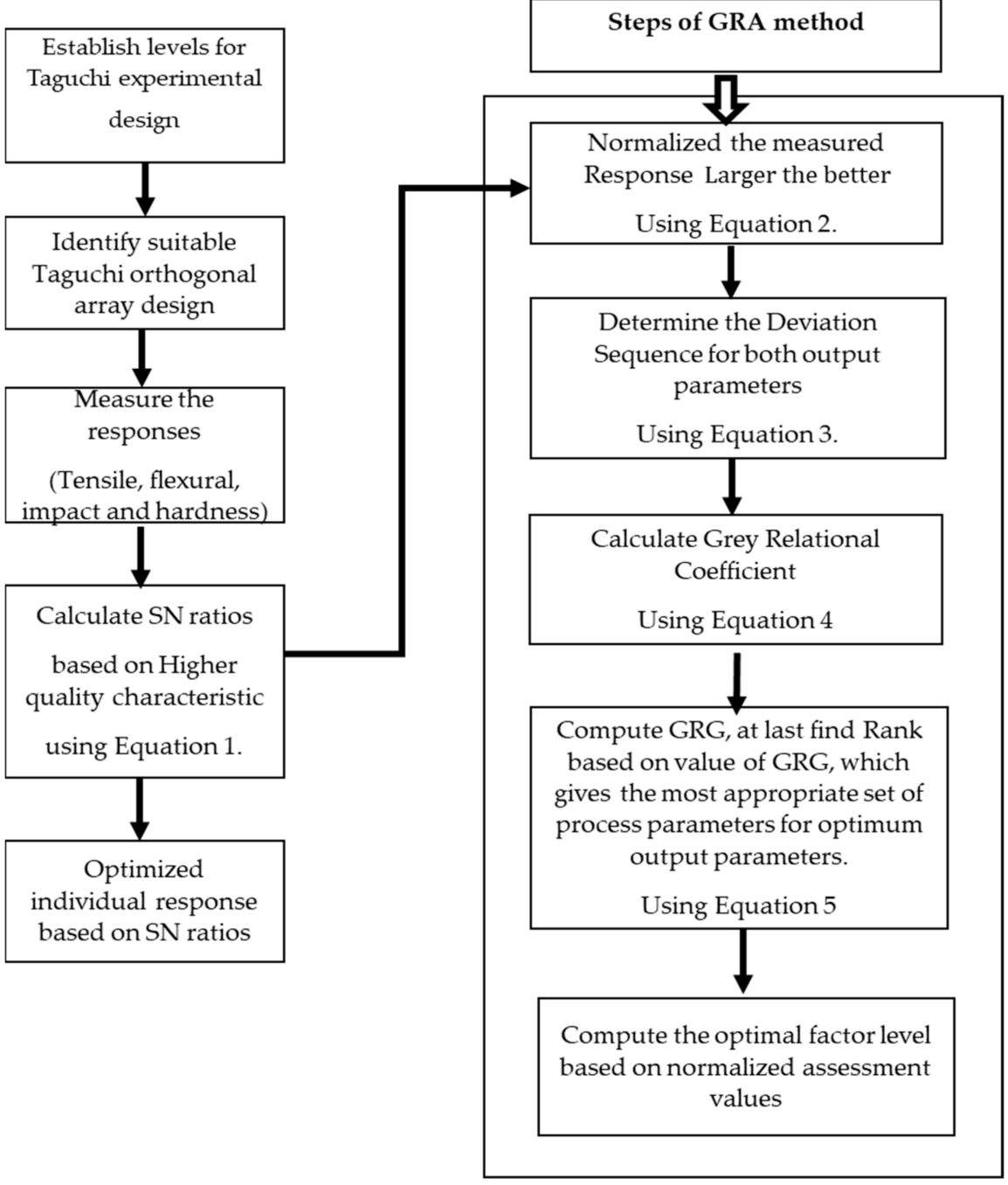

Figure 5. Methodology for optimization based on Signal-to-Noise ratios and Grey relational analysis. 


\section{Results and Discussion}

\subsection{Probability Plots and Analysis of Variance (ANOVA)}

The dispersal of experimental data for each response variable was examined considering the probability plots. The plots were constructed for each response variable at a $95 \%$ confidence interval, as shown in Figure 6. The results highlighted the data points for all measured values that fall near the fitted line, so it signifies that the results followed a normal distribution. However, a statistical test, namely Anderson-Darling (AD), is performed to further validate the normal distribution assumption of data. The $p$-value of the AD test greater than 0.05 represents a normal distribution of the input data. From the result, being the $\mathrm{AD}$ test value for each response, the $p$-value was observed greater than 0.05 , which explains that the composed data follow the normal distribution and are suitable for optimization and further analysis.
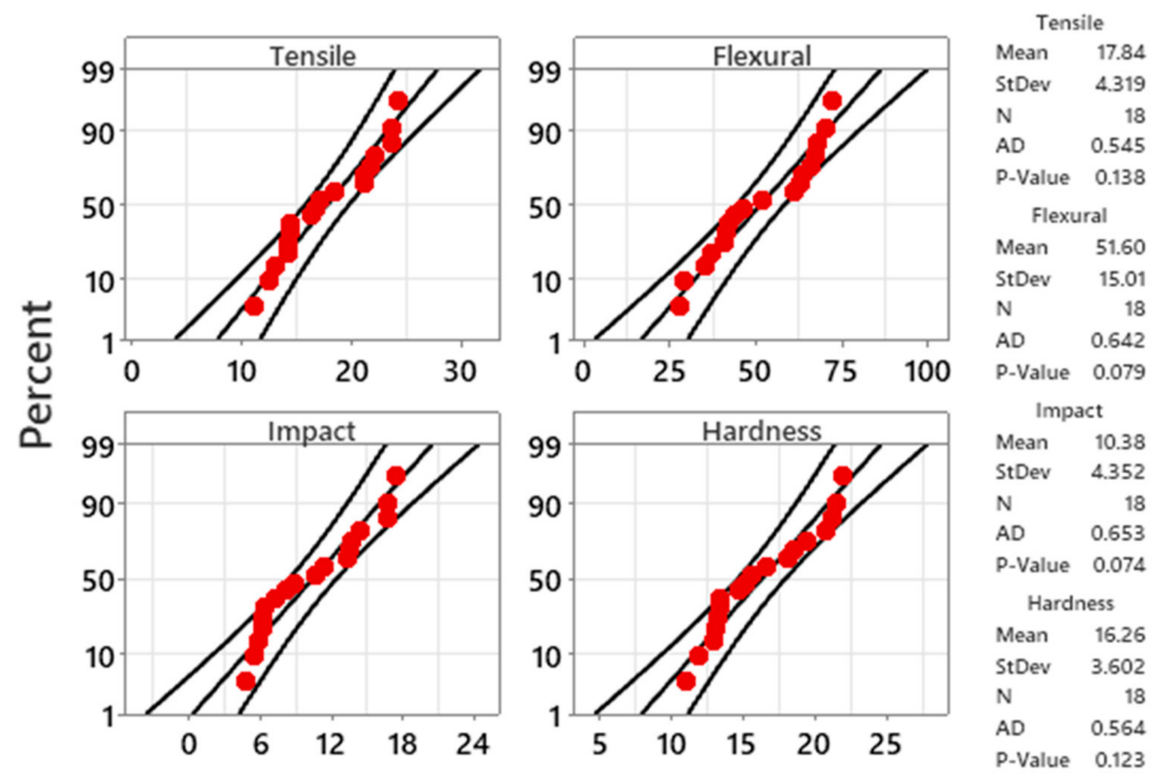

Figure 6. Probability plots for response. AD: Anderson-Darling Test.

ANOVA is performed at the $95 \%$ confidence level to study the effect of manufacturing process parameters on different responses for the wood waste composite. As shown in Table 4, the ANOVA illustrates that the wood waste percentage and wood waste type have a significant effect on all considered mechanical properties. The probability $p$-values are less than 0.05 , while the ratio of epoxy and hardener is found insignificant, as their $p$-values are greater than 0.05 .

\subsection{Tensile Strength}

The main plot for the $\mathrm{S} / \mathrm{N}$ ratio for under tensile loading (the larger the better) is shown in Figure 7a. The greater the value of the $\mathrm{S} / \mathrm{N}$ ratio corresponds to the better the quality. The optimal combination of design parameters is the wood waste type percentage at low level, i.e., $10 \%$, weight percentage ratio of epoxy, the hardener is at medium level i.e., 2.5, while the wood waste type is hard wood waste. Kumar et al. [35] also obtained the highest $\mathrm{S} / \mathrm{N}$ ratio of the tensile load at $10 \%$ of wood waste.

The main effect plot for tensile strength (Figure $7 \mathrm{~b}$ ) shows the highest tensile strength for hard wood waste. This may be attributed to the presence of pores or vessels in hardwood that provide good adsorption capacity for resin. This results in stronger bonding between hardwood powder and polymer matrix to improve the mechanical properties of composite structure [45]. Further, the hard wood has less hydrophilic group than softwood, so the interface bonding between softwood powder and hydrophobic epoxy is weak as compared to hardwood powder $[46,47]$. Tensile strength decreases with an increase in the wood waste 
type percentage from low level $1(10 \%)$ to a higher level $3(30 \%)$. This may be due to a decrease in epoxy resin percentage that binds the composite firmly [48]. The other possible reason may be the weak interfacial bonding between polymer matrix and filler contents that decreases the tensile strength of the composite. According to Huda et al. [49], the accumulation of wood powder or inadequate hydrogen bonding between wood powder and epoxy resin matrix causes a decrease in tensile strength. Accumulation of wood powder creates stress concentration zones and produces early cracks that reduce the tensile strength [50]. However, with an increase in the weight percentage ratio of epoxy and hardener, the tensile strength first increases from low level 1 (2) to medium level 2 (2.5) and then decreases with a further increase in the weight percentage ratio of epoxy-hardener to a higher level of 3 (3). According to Szabelski [51], increasing the hardener ratio in epoxy resin decreases the level of polymerization and therefore reduces the adhesion with other mixing additives.

\subsection{Flexural Strength}

Figure 8a shows the optimal combination process parameters for flexural strength, i.e., the wood waste type percentage at a low level (10\%), the weight percentage ratio of epoxy hardener at a high level (3), while the wood waste type is hard wood waste.

Table 4. Analysis of variance ANOVA (combined data of both data and wood waste composite).

\begin{tabular}{|c|c|c|}
\hline \multicolumn{3}{|c|}{ Tensile Result } \\
\hline Source & F-Value & $p$-Value \\
\hline Regression & 60.71 & 0.000 \\
\hline Wood percentage & 34.14 & 0.012 \\
\hline $\begin{array}{l}\text { Weight percent ratio of epoxy } \\
\text { and hardener }\end{array}$ & 0.15 & 0.708 \\
\hline Wood waste type & 147.86 & 0.001 \\
\hline \multicolumn{3}{|c|}{ Flexural Result } \\
\hline Source & F-Value & $p$-Value \\
\hline Regression & 45.66 & 0.024 \\
\hline Wood percentage & 9.64 & 0.008 \\
\hline $\begin{array}{l}\text { Weight percent ratio of epoxy } \\
\text { and hardener }\end{array}$ & 0.63 & 0.439 \\
\hline Wood waste type & 126.70 & 0.003 \\
\hline \multicolumn{3}{|c|}{ Impact Result } \\
\hline Source & F-Value & $p$-Value \\
\hline Regression & 109.07 & 0.000 \\
\hline Wood percentage & 48.32 & 0.03 \\
\hline $\begin{array}{l}\text { Weight percent ratio of epoxy } \\
\text { and hardener }\end{array}$ & 0.07 & 0.795 \\
\hline Wood waste type & 278.81 & 0.043 \\
\hline \multicolumn{3}{|c|}{ Hardness Result } \\
\hline Source & F-Value & $p$-Value \\
\hline Regression & 41.75 & 0.000 \\
\hline Wood percentage & 22.90 & 0.034 \\
\hline $\begin{array}{l}\text { Weight percent ratio of epoxy } \\
\text { and hardener }\end{array}$ & 0.03 & 0.859 \\
\hline Wood waste type & 102.32 & 0.009 \\
\hline
\end{tabular}




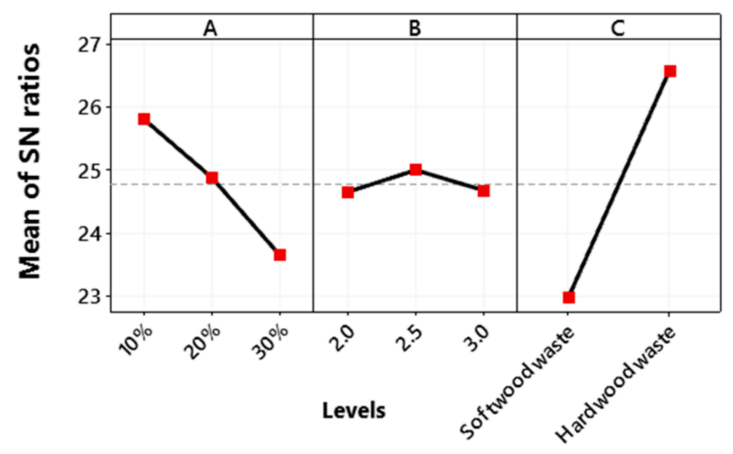

(a)

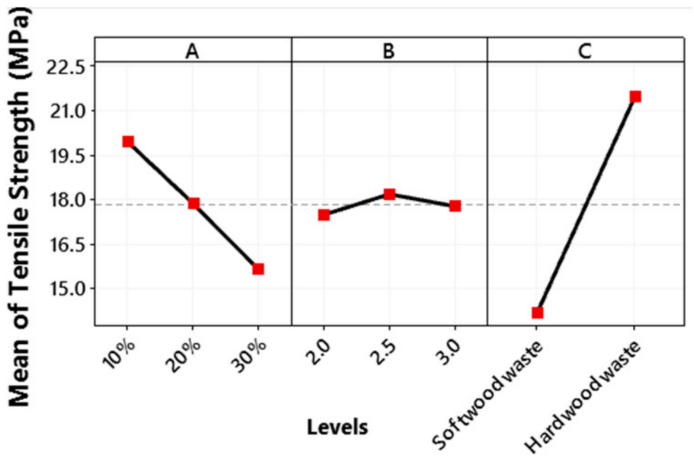

(b)

Figure 7. Main plot of tensile strength for (a) SN ratios (b) tensile strength means.

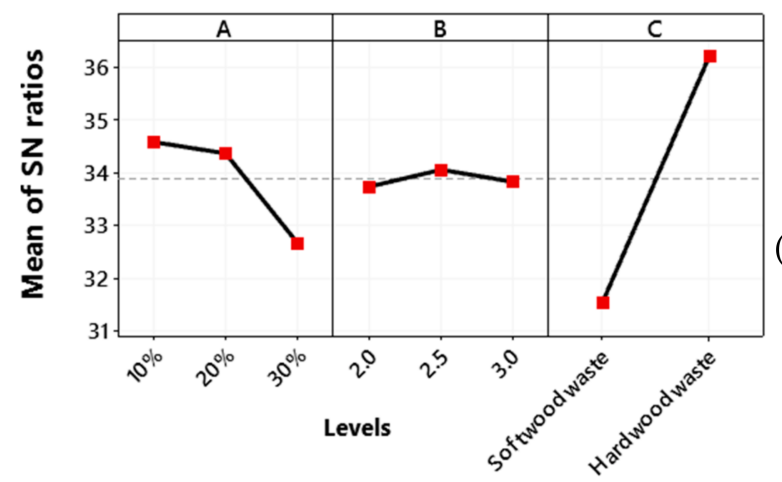

(a)

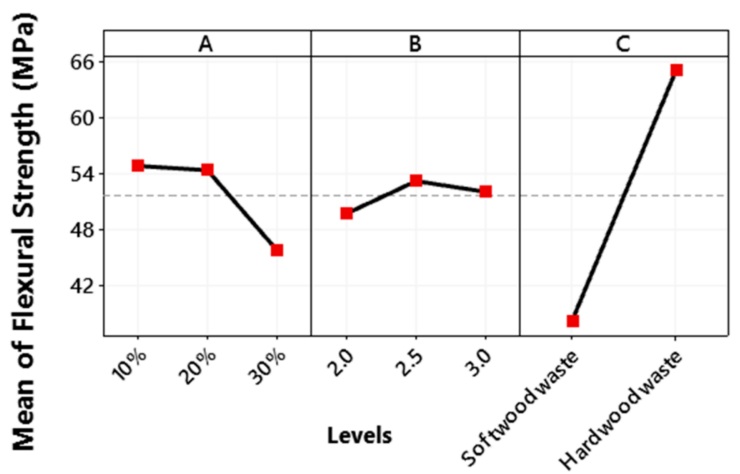

(b)

Figure 8. Main plot of flexural strength for (a) SN ratios and (b) flexural strength means.

The main effect plot for flexural strength (Figure 8b) shows the tensile strength decreases with an increase in the wood waste type percentage from a low level $1(10 \%)$ to a high level $3(30 \%)$. A high content of wood powder causes aggregation at various regions in the composite that result in weak bonding. Therefore, it produces cracks during flexural tests and reduces the load-bearing capability of composite [52,53]. The incapability of buttressing of wood powder to sustain the stresses transferred from polymer matrix and wood powder bonding create spaces between matrix materials and buttressing and results in a weak structure [54,55]. However, with an increase in the weight percentage ratio of epoxy and hardener, the flexural strength increases slightly from a low level 1 (2) to medium level (2.5). This decreases with an increase in weight percentage ratio of epoxy from medium level to a higher level of 3 (3).

\subsection{Impact Strength}

The main plot for the $\mathrm{S} / \mathrm{N}$ ratio for impact strength is shown in Figure 9a. The optimal combination of design parameters is wood waste type percentage at a low level, i.e., $10 \%$, 
the weight percentage ratio of epoxy is at medium level, i.e., 2.5, while the wood waste type is a hard wood waste.

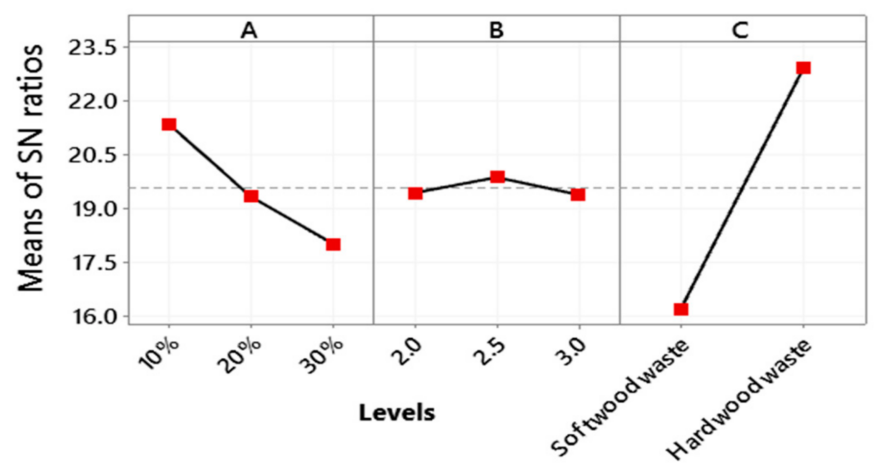

(a)

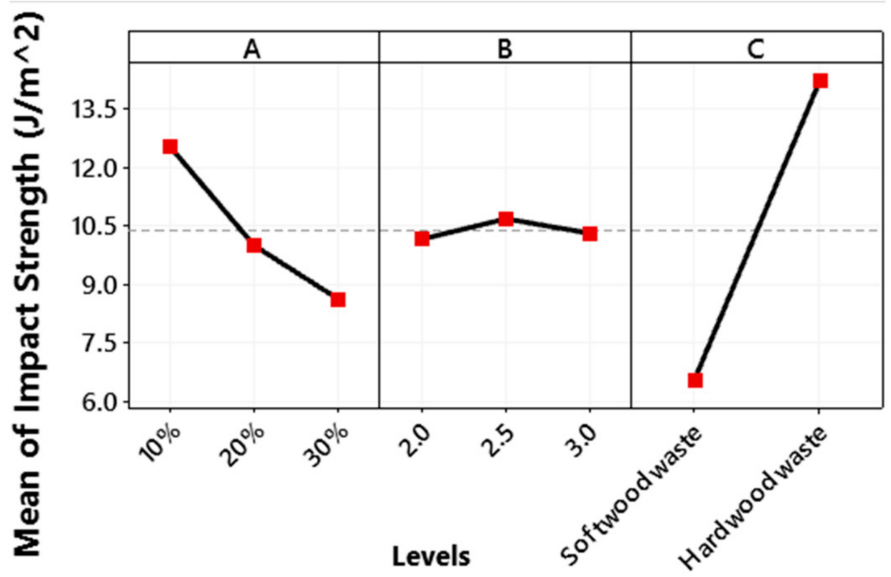

(b)

Figure 9. Main plot of impact strength for (a) SN ratios and (b) impact strength mean.

The main effect plot for means of impact strength is shown in Figure $9 \mathrm{~b}$. It shows that the highest impact strength is observed for hard wood waste. Further, tensile strength decreases with an increase in the wood waste type percentage from low level (10\%) to a high level $(30 \%)$. This may be attributed to molecular flexibility of polymer that plays a key role in determining the relative toughness and brittleness of composites [48]. The other possible reason is the formation of micro spaces at the fiber-matrix interface with an increase in wood powder that induces the crack propagation in the structure [56,57]. An increase in poor interfacial wetting decreases the impact strength of wood powder-based composites. The increase in wood ash quantity causes a brittle fracture in composite with less impact energy [48]. With the increase in weight percentage ratio of epoxy and hardener, the impact strength first increases slightly from a low level (1) and then jumps up to a medium level of 2 .

\subsection{Hardness}

Figure 10a shows the optimal combination process parameters for hardness i.e., wood waste type percentage at a low level, i.e., $10 \%$, the weight percentage ratio of epoxy is at a medium level, i.e., 2.5, while the wood waste type is a hard wood waste.

The main effect plot for flexural strength means in Figure 10b shows that the hardness decreases with an increase in the wood waste type percentage from a low level 1 (i.e., $10 \%$ ) to a high level 3 (i.e., 30\%). This is attributed to a decrease in epoxy resin percentage that binds the composite firmly [48]. An increase in wood powder makes the composite structure porous and therefore reduces the hardness of material [57]. With an increase in the weight percentage ratio of epoxy and hardener, the hardness first increases slightly from a low level 1 to a medium level 2, and then decreases with an increase in weight 
percentage ratio of epoxy from a medium level to a high level 3. The maximum hardness is observed for hard wood waste.

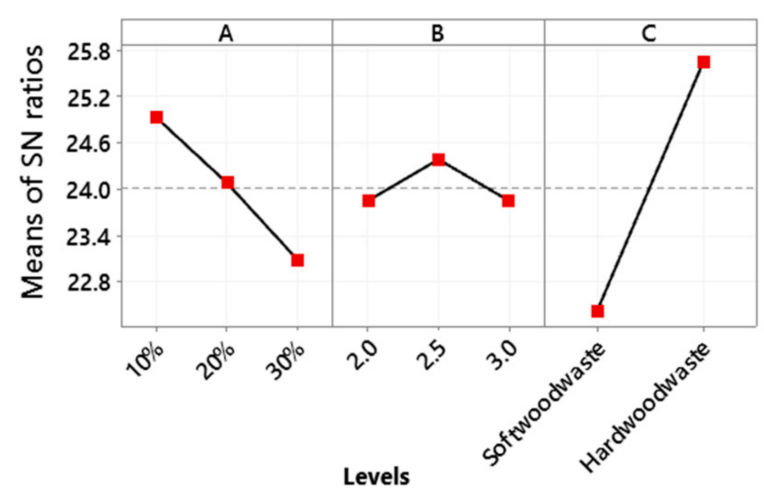

(a)

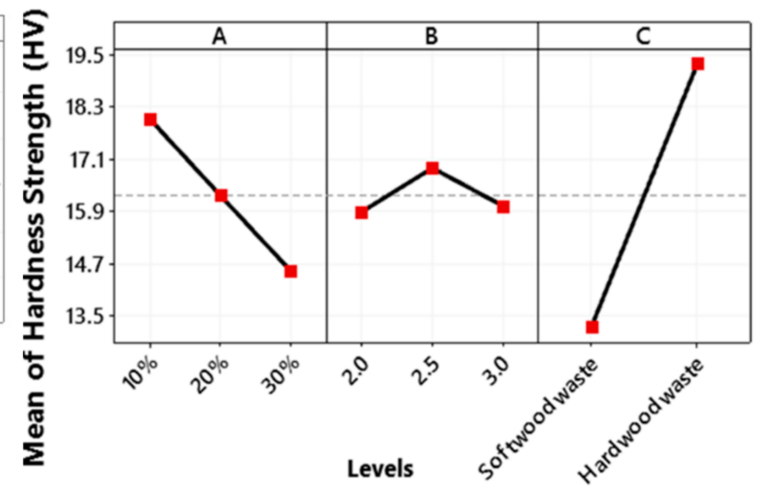

(b)

Figure 10. Main plot of hardness for (a) SN ratios and (b) hardness means.

\subsection{Multi-Response Optimization Using GRA}

As discussed in the material and methods section, the responses are optimized based on the GRA. First, the responses are normalized using Equation (2) to harmonize the units. These are shown in Table 5. In the second step, the value of the deviation sequence is attained by using Equation (3), as tabulated in Table 6. In the third step, the Grey Relational Coefficient (GRC) is obtained based on Equation (4). This was evaluated to choose the "larger the better" class that reflected the relationship between the desired test data and actual data, as shown in Table 7. In step 4, the GRG is computed using equation 5, as shown in Table 8. Higher GRG values correspond to the optimal combination of process parameters. Hence, the maximum value of GRG is computed as 0.781 in the 4 th experimental run. This indicated the wood waste type percentage at a low level, i.e., $10 \%$, the weight percentage ratio of epoxy hardener at a high level, i.e., 3, while the wood waste type is a hard wood waste.

\subsection{Thermal Testing Results}

\subsubsection{Differential Scanning Calorimetry DSC}

The data evaluation calculated through DSC analysis showed optimistic results. The phase transition of hardwood and softwood waste epoxy composite can either be exothermic or endothermic. The heat flow was measured with respect to time and glass transition temperature $\left(T_{g}\right)$, and crystallization Temperature $T_{c}$ and decomposition temperature $T_{d}$ were observed. The glass transition temperature shows the precise temperature; however, if the temperature crosses the $T_{g}$ then the material behaves like a viscous fluid. With the help of DSC machine, the change in temperature observed for these phases is shown in Figure $11 \mathrm{a}, \mathrm{b}$. The early peak from 60 to $70{ }^{\circ} \mathrm{C}$ specifies the $\mathrm{T}_{\mathrm{g}}$ of both specimens. It is observed that $\mathrm{T}_{\mathrm{g}}$ lies in between 62 to $66^{\circ} \mathrm{C}$. Finally, the highest $\mathrm{T}_{\mathrm{g}}$ is detected for $10 \%$ wood waste loading. When the waste exceeds more than $10 \%$, a decreasing tendency of $\mathrm{T}_{\mathrm{g}}$ is examined. The glass transition curve exhibited a similar trend for waste wood loading, both for a hardwood and softwood waste epoxy composite. However, it is recognized that the $\mathrm{T}_{\mathrm{g}}$ of polymer composite depends on the strength of the chain segment of organic compounds [58-60]. The glass transition curve exhibited a similar trend for waste wood loading, both for a hardwood and softwood waste epoxy composite. From basic research, due to a reduction in wood waste moisture, surface treatment of wood waste and solid interfacial bonding between wood waste and the matrix takes place, which results in improving the $\mathrm{T}_{\mathrm{g}}$. The next exothermic region found around 65 to $69^{\circ} \mathrm{C}$, as shown, with slow rate of crystallization for both hardwood and softwood waste composite; however, in order to increase, the crystallization peak needs to improve the mobility of chain segment 
in the polymer composite [61]. The next exothermic region was found around 65 to $69^{\circ} \mathrm{C}$, as the crystallization region for both hardwood and softwood waste composite.

Figure 12a,b demonstrate the decomposition temperature $T_{d}$ for both wood waste types composites. The $T_{d}$ of hardwood and softwood waste composite was around 380 to $400{ }^{\circ} \mathrm{C}$. The previous studies indicate that pure epoxy and bamboo epoxy composite exhibit dissimilar $\mathrm{T}_{\mathrm{d}}$ [36]. The bamboo fiber composite and epoxy composite exhibited exothermic peaks at temperatures $327^{\circ} \mathrm{C}$ to $354^{\circ} \mathrm{C}$. Hence, the addition of hardwood waste at A $10 \%$ improves the $\mathrm{T}_{\mathrm{d}}$, due to its strong adhesion between matrix and waste. However, the other samples C $10 \%$, C $20 \%$, C 30\%, A $20 \%$, and A $30 \%$ slightly improved the value of $\mathrm{T}_{\mathrm{d}}$.

\subsubsection{Thermogravimetric Analysis TGA}

The results of applied hardwood and softwood waste on the thermal stability of epoxy composite are evaluated through TGA. The degradation of epoxy composite exists in two stages. From the first stage, the degradation takes place at $50{ }^{\circ} \mathrm{C}$ to $100{ }^{\circ} \mathrm{C}$. This is due to the natural connection of Hemicelluloses and moisture portion [62], therefore, wood fibers existing of more Hemicelluloses content absorb further moisture and degrade at lesser temperatures. The second stage is a significant degradation stage when the organic compounds contained in the composite are decomposed; this is because of the main lignocellulose constituents [63]. However, the treatment was found to support in emitting the impurities and other low thermal content portions; different studies investigated in the chemical behavior may enhance the material thermal stability by eliminating the inoperable materials, such as non-cellulosic [64,65]. The values computed from the weight loss curves (TGA) and derivatives of weight loss (DTG) are presented in Table 9. The plots of these are shown in Figure 13a-d. The peak that appears on the DTG curves explains the maximum rate of weight loss from the specimen and generates information about its chemical structure. As a result of the increase in temperature, the dehydration occurs first, accompanied by the discharge of liquid and volatile compounds $[37,66,67]$.

Table 5. Normalized responses.

\begin{tabular}{ccccc}
\hline Experiment No. & Tensile Strength & Flexural Strength & Impact Strength & Hardness \\
\hline 1 & 0.394 & 0.365 & 0.393 & 0.340 \\
2 & 0.956 & 0.755 & 0.956 & 1.000 \\
3 & 0.455 & 0.409 & 0.454 & 0.424 \\
4 & 1.000 & 0.906 & 1.000 & 0.974 \\
5 & 0.228 & 0.302 & 0.228 & 0.182 \\
6 & 0.954 & 0.893 & 0.954 & 0.943 \\
7 & 0.246 & 0.321 & 0.245 & 0.222 \\
8 & 0.763 & 0.792 & 0.762 & 0.696 \\
9 & 0.244 & 0.289 & 0.244 & 0.218 \\
10 & 0.797 & 1.000 & 0.796 & 0.901 \\
11 & 0.236 & 0.201 & 0.235 & 0.202 \\
12 & 0.757 & 0.962 & 0.756 & 0.655 \\
14 & 0.091 & 0.164 & 0.091 & 0.076 \\
15 & 0.422 & 0.541 & 0.421 & 0.380 \\
16 & 0.141 & 0.000 & 0.140 & 0.178 \\
17 & 0.551 & 0.805 & 0.550 & 0.518 \\
18 & 0.000 & 0.025 & 0.000 & 0.000 \\
\end{tabular}

The thermal degradation of the hardwood and softwood waste epoxy composite was determined based on TGA temperature profiles corresponding to $5 \%, 10 \%$, and $50 \%$ weight. The largest temperature value was recorded on hardwood waste A $10 \%$ and softwood waste composite C $30 \%$. Regardless of the wood waste type and quantity of wood waste, the temperature of $5 \%$ weight loss was more than $150{ }^{\circ} \mathrm{C}$, which is higher than the predictable temperature of the utilization of epoxy composites. Additionally, it was analyzed that the material shows maximum thermal stability in the temperature range around $300{ }^{\circ} \mathrm{C}$. The higher temperature values were obtained for the $\mathrm{C} 10 \%, \mathrm{C} 20 \%$, and A $20 \%$ among the epoxy composites. Hence, the degradation characteristics of different lignocellulosic fibers are possibly assessed based on their chemical composition. Therefore, 
it is credible that alterations in thermal stability of composite samples from different wood species can be attributed to dissimilarities and variations in the chemical composition of timber components and additionally, can also affect the thermal performance wood polymer composites [68].

Table 6. Deviation sequence analysis for responses.

\begin{tabular}{ccccc}
\hline Experiment No. & Tensile Strength & Flexural Strength & Impact Strength & Hardness \\
\hline 1 & 0.606 & 0.635 & 0.394 & 0.660 \\
2 & 0.044 & 0.245 & 0.956 & 0.000 \\
3 & 0.545 & 0.591 & 0.455 & 0.576 \\
4 & 0.000 & 0.094 & 1.000 & 0.026 \\
5 & 0.772 & 0.698 & 0.228 & 0.817 \\
6 & 0.046 & 0.107 & 0.954 & 0.057 \\
7 & 0.754 & 0.679 & 0.246 & 0.778 \\
8 & 0.237 & 0.208 & 0.763 & 0.304 \\
9 & 0.756 & 0.711 & 0.244 & 0.781 \\
10 & 0.203 & 0.000 & 0.797 & 0.098 \\
11 & 0.764 & 0.799 & 0.236 & 0.798 \\
12 & 0.243 & 0.038 & 0.757 & 0.345 \\
13 & 0.909 & 0.836 & 0.091 & 0.923 \\
14 & 0.578 & 0.459 & 0.422 & 0.619 \\
16 & 0.859 & 1.000 & 0.141 & 0.821 \\
17 & 0.449 & 0.195 & 0.551 & 0.481 \\
\end{tabular}

Table 7. Grey relational coefficients for responses.

\begin{tabular}{ccccc}
\hline Experiment No. & Tensile Strength & Flexural Strength & Impact Strength & Hardness \\
\hline 1 & 0.452 & 0.440 & 0.560 & 0.431 \\
2 & 0.920 & 0.671 & 0.343 & 1.000 \\
3 & 0.478 & 0.458 & 0.524 & 0.465 \\
4 & 1.000 & 0.841 & 0.333 & 0.951 \\
5 & 0.393 & 0.417 & 0.687 & 0.380 \\
6 & 0.916 & 0.824 & 0.344 & 0.898 \\
7 & 0.399 & 0.424 & 0.670 & 0.391 \\
8 & 0.678 & 0.707 & 0.396 & 0.622 \\
9 & 0.398 & 0.413 & 0.672 & 0.390 \\
10 & 0.711 & 1.000 & 0.386 & 0.836 \\
11 & 0.396 & 0.385 & 0.680 & 0.385 \\
12 & 0.673 & 0.930 & 0.398 & 0.592 \\
13 & 0.355 & 0.374 & 0.846 & 0.351 \\
15 & 0.464 & 0.521 & 0.542 & 0.447 \\
16 & 0.368 & 0.333 & 0.780 & 0.378 \\
18 & 0.527 & 0.719 & 0.476 & 0.510 \\
\hline
\end{tabular}

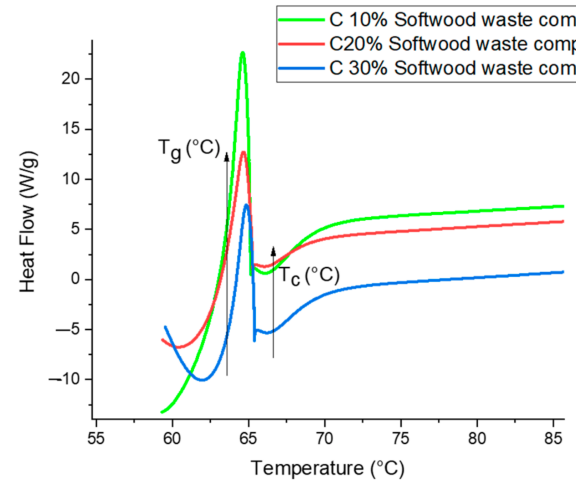

(a)

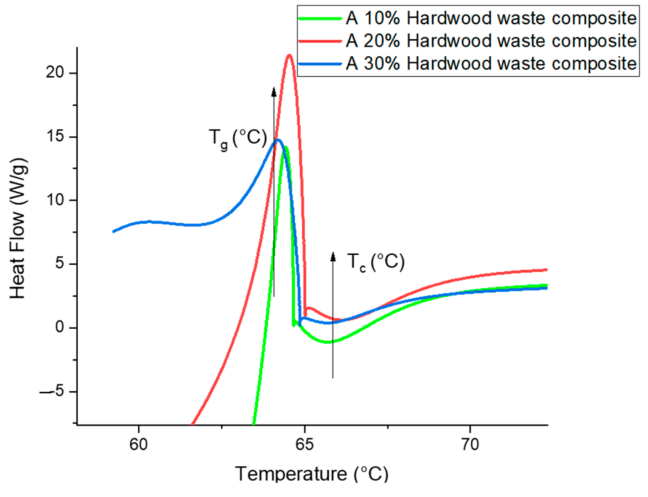

(b)

Figure 11. (a) Glass transition temperature $\left(\mathrm{T}_{\mathrm{g}}\right)$ and crystallization temperature $\mathrm{T}_{\mathrm{C}}$ of softwood waste filled in composite. (b) Glass transition temperature $\mathrm{T}_{\mathrm{g}}$ and crystallization temperature $\mathrm{T}_{\mathrm{C}}$ of hardwood waste filled in composite. 
Table 8. GRG and Ranks.

\begin{tabular}{ccc}
\hline Experiment No. & Grey Relational Grade GRG & Ranks \\
\hline 1 & 0.471 & 14 \\
2 & 0.733 & 3 \\
3 & 0.481 & 12 \\
4 & 0.781 & 1 \\
5 & 0.469 & 15 \\
6 & 0.746 & 2 \\
7 & 0.471 & 13 \\
8 & 0.601 & 7 \\
9 & 0.468 & 16 \\
10 & 0.733 & 4 \\
11 & 0.461 & 18 \\
12 & 0.648 & 6 \\
13 & 0.482 & 11 \\
14 & 0.494 & 10 \\
15 & 0.465 & 17 \\
16 & 0.558 & 8 \\
17 & 0.501 & 9 \\
18 & 0.651 & 5 \\
\hline
\end{tabular}

Table chart 11 with the residue at $700{ }^{\circ} \mathrm{C}$ shows an increased value in organic compounds in the proportion to the amount of lignin contained in it. This is accompanied by the presence of aromatic groups in lignin, the existence of which promotes the formation of char [69].

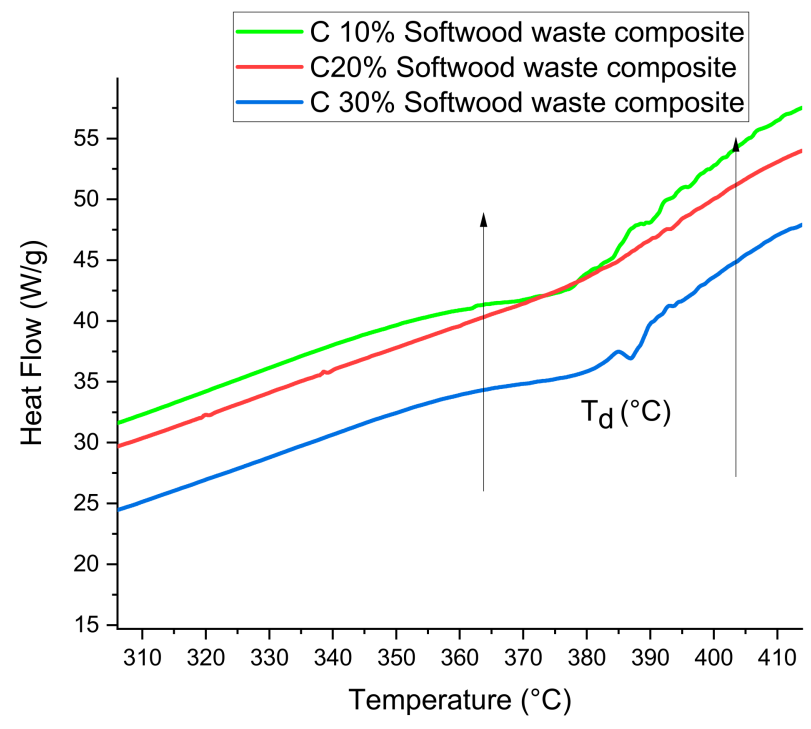

(a)

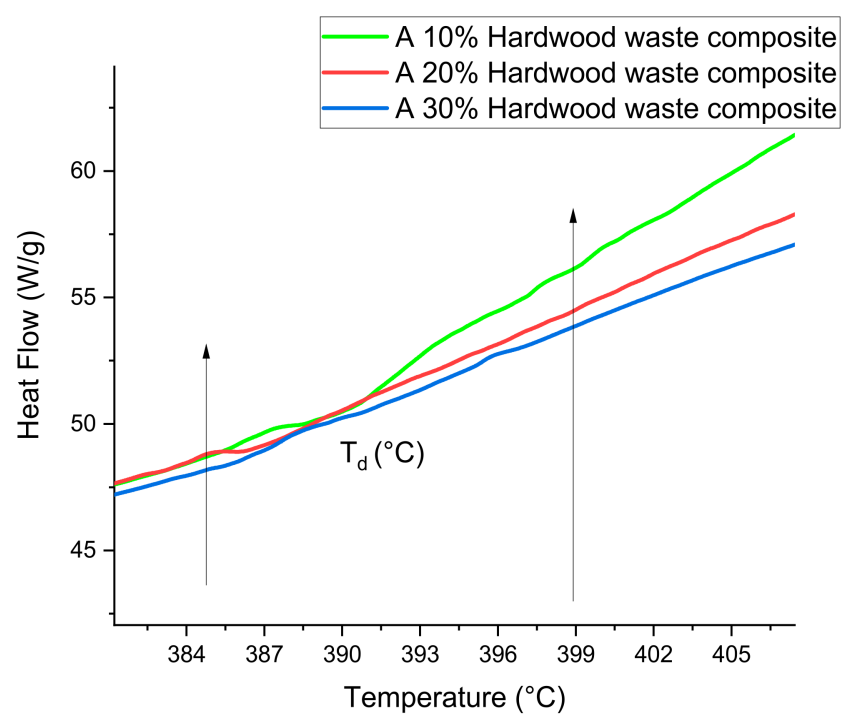

(b)

Figure 12. (a) Decomposition temperature $T_{d}$ of softwood waste filled in composite. (b) Decomposition temperature $T_{d}$ of hardwood waste filled in composite.

Table 9. Weight loss temperature (TGA) at 5\%,10\%, and 50\%, and derivation of peak weight loss (DTG).

\begin{tabular}{|c|c|c|c|c|c|}
\hline Sample & $5 \%$ Weight Loss, ${ }^{\circ} \mathrm{C}$ & $10 \%$ Weight Loss, ${ }^{\circ} \mathrm{C}$ & $50 \%$ Weight Loss, ${ }^{\circ} \mathrm{C}$ & Derivative of Weight Loss (DTG), ${ }^{\circ} \mathrm{C}$ & Residual Sample Weight $700^{\circ} \mathrm{C}$ \\
\hline A $10 \%$ & $227.6^{\circ} \mathrm{C}$ & $313.2^{\circ} \mathrm{C}$ & $379.9^{\circ} \mathrm{C}$ & $377^{\circ} \mathrm{C}$ & $4.50 \%$ \\
\hline A $20 \%$ & $175.9^{\circ} \mathrm{C}$ & $271.3^{\circ} \mathrm{C}$ & $376.1^{\circ} \mathrm{C}$ & $376^{\circ} \mathrm{C}$ & $9.07 \%$ \\
\hline A $30 \%$ & $209.5^{\circ} \mathrm{C}$ & $315.24{ }^{\circ} \mathrm{C}$ & $383.5^{\circ} \mathrm{C}$ & $374^{\circ} \mathrm{C}$ & $6.77 \%$ \\
\hline C $10 \%$ & $175.2^{\circ} \mathrm{C}$ & $278.5^{\circ} \mathrm{C}$ & $381.2^{\circ} \mathrm{C}$ & $381^{\circ} \mathrm{C}$ & $7.63 \%$ \\
\hline C $20 \%$ & $173.1^{\circ} \mathrm{C}$ & $263.9^{\circ} \mathrm{C}$ & $377.8^{\circ} \mathrm{C}$ & $380^{\circ} \mathrm{C}$ & $9.54 \%$ \\
\hline C $30 \%$ & $228.6^{\circ} \mathrm{C}$ & $329.7^{\circ} \mathrm{C}$ & $382.8^{\circ} \mathrm{C}$ & $378^{\circ} \mathrm{C}$ & $7.88 \%$ \\
\hline
\end{tabular}




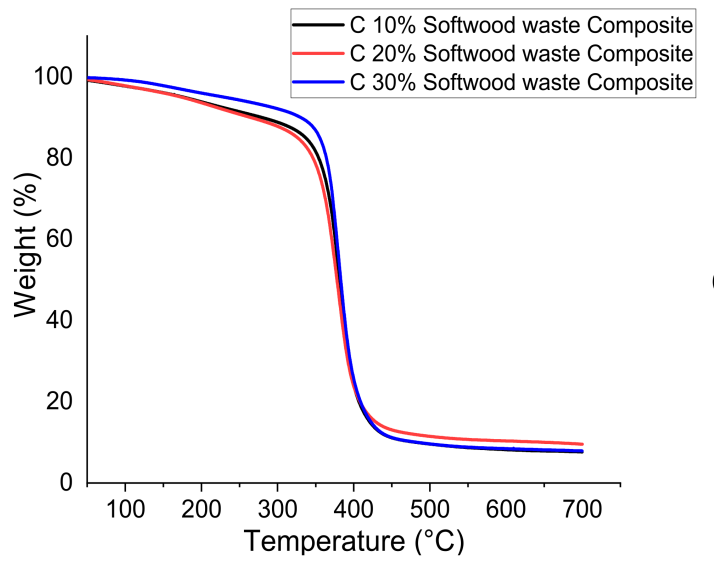

(a)

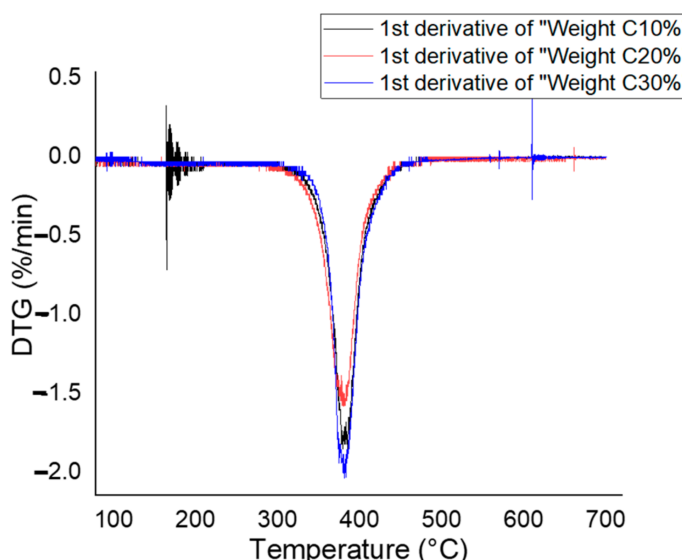

(b)

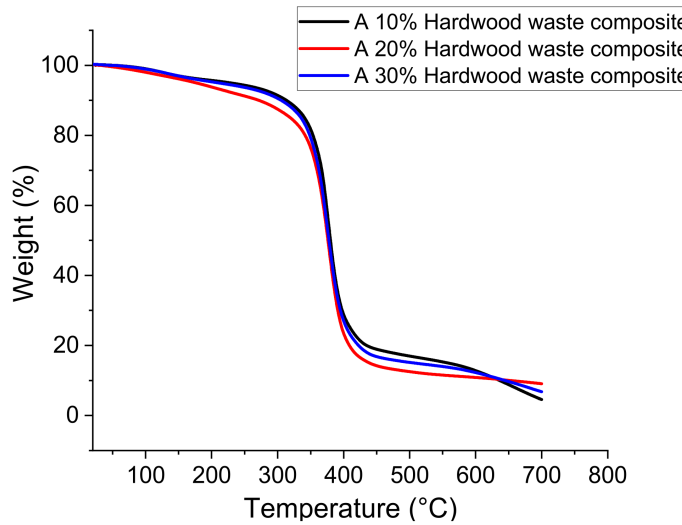

(c)

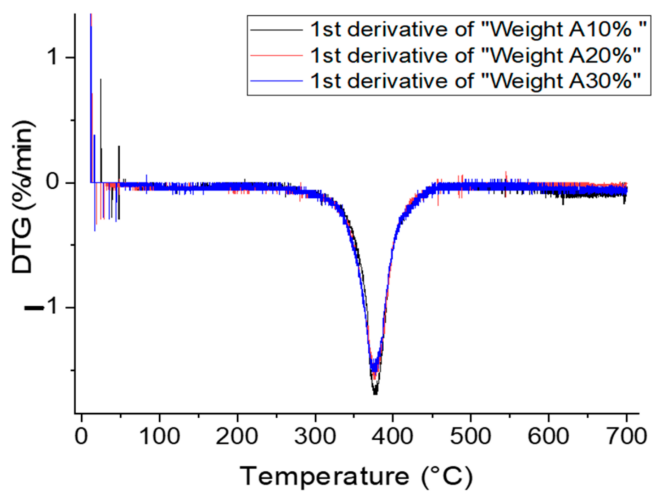

(d)

Figure 13. (a) Weight loss curves for soft wood. (b) Derivative of weight loss DTG for softwood waste composite. (c) Weight loss curves for hard wood waste. (d) Derivative of weight loss DTG for hardwood waste composite. 


\section{Conclusions}

Several compositions of wood waste composites were analyzed by varying the weight ratios of epoxy and hardener. From these compositions, it can be concluded that the epoxybased composite samples manufactured with both types of wood waste (acacia and cedar) show adequate mechanical strength and thermal performance.

From the statistical analysis, it was observed that hardwood waste in the epoxy binder has substantial impacts on the tensile strength, flexural strength, impact strength, and hardness. The thermal properties of wood waste epoxy based-composites studied with TGA and DSC characterizations predicted promising results. The results illustrate that the thermal degradation of the hardwood and softwood waste epoxy composite is prominent at the temperature values that correspond to $5 \%, 10 \%$, and 50\% weight loss (noted from the TGA curve). In the region I degradation $\left(\mathrm{T}<150{ }^{\circ} \mathrm{C}\right)$, evaporation of water molecules occurs below $100{ }^{\circ} \mathrm{C}$ in acacia and cedar waste epoxy based-composites. The final degradation temperature of both types of wood waste composites was observed at 380 to $400{ }^{\circ} \mathrm{C}$.

The phase transitions of hardwood and softwood $\left(T_{g}, T_{c}\right.$, and $\left.T_{d}\right)$ were observed cautiously. It was observed that $\mathrm{T}_{\mathrm{g}}$ of both wood waste composites lie between 62 and $66^{\circ} \mathrm{C}$. A higher value of the $\mathrm{T}_{\mathrm{g}}$ was observed at $10 \%$ waste loading. It was also noted that an increase of hard wood waste improved the value of $T_{d}$, due to strong adhesion between waste and matrix.

Author Contributions: M.U.K. conceived and designed the experimentation. W.S. supported numerical simulation work, edited, and proofread the first draft, and supervised the complete research project. S.N. worked on experimental findings and suggested the material behavior laws. M.A. and R.K. helped in bibliography and compiling results. S.N. and B.S. proofread the manuscript and made significant changes to improve the quality of the paper. All authors have read and agreed to the published version of the manuscript.

Funding: This study received funding from King Saud University, Saudi Arabia, through researchers supporting project number (RSP-2021/145). Additionally, the APCs were funded by King Saud University, Saudi Arabia, through researchers supporting project number (RSP-2021/145).

Institutional Review Board Statement: Not applicable.

Informed Consent Statement: Not applicable.

Data Availability Statement: The data presented in this study are available on request from the corresponding authors.

Acknowledgments: The authors extend their appreciation to King Saud University, Saudi Arabia for funding this work through researchers supporting project number (RSP-2021/145).

Conflicts of Interest: The authors declare no conflict of interest.

\section{References}

1. Laleicke, P.F. Wood waste, the challenges of communication and innovation. BioResources 2018, 13, 2182-2183. [CrossRef]

2. Burnard, M.; Tavzes, Č.; Tošić, A.; Brodnik, A.; Kutnar, A. The Role of Reverse Logistics in Recycling of Wood Products; IAM-Inštitut Andrej Marušič: Koper, Slovenija, 2015; ISBN 9789812876430.

3. United Nations Sustainable Development Golas (SDGs). 2018. Available online: https://www.undp.org/sustainabledevelopment-goals (accessed on 2 February 2021).

4. Top, Y.; Adanur, H.; Oz, M. Type, Quantity, and Re-Use of Residues in the Forest Products Industry in Trabzon, Turkey. BioResources 2018, 13, 1745-1760. [CrossRef]

5. Liang, W.; Lv, M.; Yang, X. The combined effects of temperature and humidity on initial emittable formaldehyde concentration of a medium-density fiberboard. Build. Environ. 2016, 98, 80-88. [CrossRef]

6. Silva, D.A.L.; Lahr, F.A.R.; Varanda, L.D.; Christoforo, A.L.; Ometto, A.R. Environmental performance assessment of the melamine-urea-formaldehyde (MUF) resin manufacture: A case study in Brazil. J. Clean. Prod. 2015, 96, 299-307. [CrossRef]

7. Salles Ferro, F.; Hendrigo de Almeida, T.; Henrique de Almeida, D.; Luis Christoforo, A.; Antonio Rocco Lahr, F. Physical Properties of OSB Panels Manufactured with CCA and CCB Treated Schizolobium amazonicum and Bonded with Castor Oil Based Polyurethane Resin. Int. J. Mater. Eng. 2016, 6, 151-154. [CrossRef]

8. Song, X.; Zheng, S.; Huang, J.; Zhu, P.; Guo, Q. Miscibility, morphology and fracture toughness of tetrafunctional epoxy resin/poly (styrene-co-acrylonitrile) blends. J. Mater. Sci. 2000, 35, 5613-5619. [CrossRef] 
9. Morgan, R.J.; Mones, E.T.; Steele, W.J. Tensile deformation and failure processes of amine-cured epoxies. Polymer 1982, 23, 295-305. [CrossRef]

10. Gledhill, R.A.; Kinloch, A.J.; Yamini, S.; Young, R.J. Relationship between mechanical properties of and crack progogation in epoxy resin adhesives. Polymer 1978, 19, 574-582. [CrossRef]

11. Abba, H.A.; Nur, I.Z.; Salit, S.M. Review of Agro Waste Plastic Composites Production. Sci. Res. 2013, 1, 37218. [CrossRef]

12. Bledzki, A.K.; Faruk, O. Wood Fiber Reinforced Polypropylene Composites: Compression and Injection Molding Process. Polym.-Plast. Technol. Eng. 2007, 43, 37-41. [CrossRef]

13. Ismail, H.; Mega, L.; Abdul Khalil, H.P.S. Effect of a silane coupling agent on the properties of white rice husk ashpolypropylene/natural rubber composites. Polym. Int. 2001, 50, 606-611. [CrossRef]

14. Deraman, M. Chemical Modification on Lignocellulosic Polymeric Oil Palm Empty Fruit Bunch for Advanced Material. Adv. Polym. Technol. 2001, 20, 289-295.

15. Salasinska, K.; Barczewski, M.; Borucka, M.; Górny, R.L.; Kozikowski, P.; Celiński, M.; Gajek, A. Thermal stability, fire and smoke behaviour of epoxy composites modified with plant waste fillers. Polymers 2019, 11, 1234. [CrossRef]

16. Sapuan, S.M.; Harimi, M.; Maleque, M.A. Mechanical properties of epoxy/coconut shell filler particle composites. Arab. J. Sci. Eng. 2003, 28, 171-181.

17. Ramesh, P.; Prasad, B.D.; Narayana, K.L. Morphological and mechanical properties of treated kenaf fiber/MMT clay reinforced PLA hybrid biocomposites. AIP Conf. Proc. 2019, 2057, 020035. [CrossRef]

18. Seretis, G.; Kouzilos, G.; Manolakos, D.; Provatidis, C. Multi-objective curing cycle optimization for glass fabric/epoxy composites using poisson regression and genetic algorithm. Mater. Res. 2018, 21, e20170815. [CrossRef]

19. Dehnad, K. Quality Control, Robust Design, and the Taguchi Method; Springer: New York, NY, USA, 1989; ISBN 978-1-4684-1472-1.

20. Antony, J.; Warwood, S.; Fernandes, K.; Rowlands, H.; Antony, J. Work Study Emerald Article: Process optimisation using Taguchi methods of experimental design Process optimisation using Taguchi methods of experimental design. Work Study 2007, 20, 51-58.

21. Park, Y.; Yum, B. Development of performance measures for dynamic parameter design problems. Int. J. Manuf. Technol. Manag. 2003, 5, 91-104. [CrossRef]

22. Ogorkiewicz, R. Thermoplastics: Properties and Design; John Wiley and Sons: Hoboken, NJ, USA, 1974; ISBN 9780471653066.

23. Mishra, V.R. Utilization of waste saw dust in development of epoxy resin hybrid green composite. Mater. Today Proc. 2019, 25, 799-803. [CrossRef]

24. Berns, R.S. Billmeyer and Saltzman's Principles of Color; John Wiley \& Sons Inc.: Hoboken, NJ, USA, $1967 ;$ ISBN 9781119367314.

25. Borysiak, S.; Paukszta, D.; Helwig, M. Flammability of wood-polypropylene composites. Polym. Degrad. Stab. 2006, 91, 3339-3343. [CrossRef]

26. Nabi Saheb, D.; Jog, J.P. Natural fiber polymer composites: A review. Adv. Polym. Technol. 1999, 18, 351-363. [CrossRef]

27. Müller, L.; Rubio-Pérez, G.; Bach, A.; Muñoz-Rujas, N.; Aguilar, F.; Worlitschek, J. Consistent DSC and TGA methodology as basis for the measurement and comparison of thermo-physical properties of phase change materials. Materials 2020, 13, 4486. [CrossRef]

28. Fröberg, L. Thermal Analysis TGA/DTA; Åbo Akademi University: Turku, Finland, 2010.

29. Fernández, J.M.; Plaza, C.; Polo, A.; Plante, A.F. Use of thermal analysis techniques (TG-DSC) for the characterization of diverse organic municipal waste streams to predict biological stability prior to land application. Waste Manag. 2012, 32, 158-164. [CrossRef]

30. Shahzad, A. A study in physical and mechanical properties of hemp fibres. Adv. Mater. Sci. Eng. 2013, 2013, 325085. [CrossRef]

31. Oliveira, A.K.F.; d'Almeida, J.R.M. Characterization of ubuçu (Manicaria saccifera) natural fiber mat. Polym. Renew. Resour. 2014, 5, 13-28. [CrossRef]

32. Waseem, M.; Salah, B.; Habib, T.; Saleem, W.; Abas, M.; Khan, R.; Ghani, U.; Siddiqi, M.U.R. Multi-Response Optimization of Tensile Creep Behavior of PLA 3D Printed Parts Using Categorical Response Surface Methodology. Polymers 2020, $12,2962$. [CrossRef]

33. Erden, A.; Ho, K. 3 Fiber reinforced composites. In Fiber Technology for Fiber-Reinforced Composites; Woodhead Publishing: Cambridge, UK, 2017; pp. 51-79.

34. Suddell, B.C.; Evans, W.J. Natural fiber composites in automotive applications. In Natural Fibres in Biopolymers $\mathcal{E}$ Their BioComposites; CRC Press: Boca Raton, FL, USA, 2005; pp. 231-259. [CrossRef]

35. Kumar, R.; Kumar, K.; Bhowmik, S. Optimization of Mechanical Properties of Epoxy based Wood Dust Reinforced Green Composite Using Taguchi Method. Procedia Mater. Sci. 2014, 5, 688-696. [CrossRef]

36. Shah, A.U.M.; Sultan, M.T.H.; Cardona, F.; Jawaid, M.; Talib, A.R.A.; Yidris, N. Thermal analysis of bamboo fibre and its composites. BioResources 2017, 12, 2394-2406. [CrossRef]

37. Chapple, S.; Anandjiwala, R. Flammability of natural fiber-reinforced composites and strategies for fire retardancy: A review. J. Thermoplast. Compos. Mater. 2010, 23, 871-893. [CrossRef]

38. Amariutei, O.A.; Ramsdale-Capper, R.; Correa Álvarez, M.; Chan, L.K.Y.; Foreman, J.P. Modelling the properties of a difunctional epoxy resin cured with aromatic diamine isomers. Polymer 2018, 156, 203-213. [CrossRef]

39. Singh, K.P.; Singh, A.; Kumar, N.; Tripathi, D.N. Morphological features, dielectric and thermal properties of epoxy-copper cobaltite nanocomposites: Preparation and characterization. Bull. Mater. Sci. 2020, 43, 114. [CrossRef] 
40. Liu, Y.; Via, B.K.; Pan, Y.; Cheng, Q.; Guo, H.; Auad, M.L.; Taylor, S. Preparation and characterization of epoxy resin cross-linked with high wood pyrolysis bio-oil substitution by acetone pretreatment. Polymers 2017, 9, 106. [CrossRef]

41. Davis, R.; John, P. Application of Taguchi-Based Design of Experiments for Industrial Chemical Processes. In Statistical Approaches With Emphasis on Design of Experiments Applied to Chemical Processes; IntechOpen: London, UK, 2018. [CrossRef]

42. Box, G. Signal-to- noise ratios, performance criteria, and transformations. Technometrics 1988, 30, 1-17. [CrossRef]

43. $\mathrm{Ng}$, D.K.W. Grey system and grey relational model. ACM SIGICE Bull. 1994, 20, 2-9. [CrossRef]

44. Chang, C.K.; Lu, H.S. Design optimization of cutting parameters for side milling operations with multiple performance characteristics. Int. J. Adv. Manuf. Technol. 2007, 32, 18-26. [CrossRef]

45. Ülker, O. Wood Adhesives and Bonding Theory. In Adhesives-Applications and Properties; IntechOpen: London, UK, 2016. [CrossRef]

46. Stark, N.M.; Rowlands, R.E. Effects of wood fiber characteristics on mechanical properties of wood/polypropylene composites. Wood Fiber Sci. 2003, 35, 167-174.

47. Bajpai, P. Environmentally Benign Approaches for Pulp Bleaching, 2nd ed.; Elsevier: Amsterdam, The Netherlands, 2012.

48. Sanusi, O.M.; Kofoworola Oyinlola, A.; Akindapo, J.O. Influence of Wood Ash on the Mechanical Properties of Polymer Matrix Composite Developed from Fibre Glass and Epoxy Resin. Int. J. Eng. Res. Technol. 2013, 2, 344-352.

49. Huda, M.S.; Drzal, L.T.; Misra, M.; Mohanty, A.K. Wood-fiber-reinforced poly(lactic acid) composites: Evaluation of the physicomechanical and morphological properties. J. Appl. Polym. Sci. 2006, 102, 4856-4869. [CrossRef]

50. Alsa, S.A.H. Heat and Chemical Treatments for Sawdust/UPE Composites. Eng. Technol. J. 2016, 34, $1624-1636$.

51. Szabelski, J. Effect of incorrect mix ratio on strength of two component adhesive Butt-Joints tested at elevated temperature. MATEC Web Conf. 2018, 244, 01019. [CrossRef]

52. Gobikannan, T.; Berihun, H.; Aklilu, E.; Pawar, S.J.; Akele, G.; Agazie, T.; Bihonegn, S. Development and Characterization of Sisal Fiber and Wood Dust Reinforced Polymeric Composites. J. Nat. Fibers 2021, 18, 1924-1933. [CrossRef]

53. Hossain, M.R.; Hossain, F.; Islam, M.A. Effects of Wood Properties on the Behaviors of Wood Particle Reinforced Polymer Matrix Composites. J. Sci. Res. 2014, 6, 431-443. [CrossRef]

54. Shakuntala, O.; Raghavendra, G.; Samir Kumar, A. Effect of filler loading on mechanical and tribological properties of wood apple shell reinforced epoxy composite. Adv. Mater. Sci. Eng. 2014, 2014, 538651. [CrossRef]

55. Parida, C.; Dash, S.K.; Mohanta, K.L.; Patra, S. Effect of fiber treatment and fiber content on flexural properties of Luffa cylindrica-Reinforced resorcinol composites. Adv. Sci. Lett. 2016, 22, 454-457. [CrossRef]

56. Das, S.C.; Paul, D.; Fahad, M.M.; Das, M.K.; Rahman, G.M.S.; Khan, M.A. Effect of Fiber Loading on the Dynamic Mechanical Properties of Jute Fiber Reinforced Polypropylene Composites. Adv. Chem. Eng. Sci. 2018, 08, 215-224. [CrossRef]

57. Islam, M.N.; Islam, M.S. Characterization of chemically modified sawdust-reinforced recycled polyethylene composites. J. Thermoplast. Compos. Mater. 2015, 28, 1135-1153. [CrossRef]

58. Oudia, A.; Mészáros, E.; Simões, R.; Queiroz, J.; Jakab, E. Pyrolysis-GC/MS and TG/MS study of mediated laccase biodelignification of Eucalyptus globulus kraft pulp. J. Anal. Appl. Pyrolysis 2007, 78, 233-242. [CrossRef]

59. Oliveira, M.S.; Pereira, A.C.; Monteiro, S.N.; da Costa Garcia Filho, F.; da Cruz Demosthenes, L.C. Thermal Behavior of Epoxy Composites Reinforced with Fique Fabric by DSC. In Green Materials Engineering; Springer: Berlin/Heidelberg, Germany, 2019; pp. 101-106.

60. Revanth, J.S.; Madhav, V.S.; Sai, Y.K.; Krishna, D.V.; Srividya, K.; Sumanth, C.H.M. TGA and DSC analysis of vinyl ester reinforced by Vetiveria zizanioides, jute and glass fiber. Mater. Today Proc. 2020, 26, 460-465. [CrossRef]

61. Xu, J.-Z.; Zhang, Z.-J.; Xu, H.; Chen, J.-B.; Ran, R.; Li, Z.-M. Highly enhanced crystallization kinetics of poly (l-lactic acid) by poly (ethylene glycol) grafted graphene oxide simultaneously as heterogeneous nucleation agent and chain mobility promoter. Macromolecules 2015, 48, 4891-4900. [CrossRef]

62. Ornaghi, H.L.; Poletto, M.; Zattera, A.J.; Amico, S.C. Correlation of the thermal stability and the decomposition kinetics of six different vegetal fibers. Cellulose 2014, 21, 177-188. [CrossRef]

63. Kamalbabu, P.; Kumar, G.C.M. Effects of Particle Size on Tensile Properties of Marine Coral Reinforced Polymer Composites. Procedia Mater. Sci. 2014, 5, 802-808. [CrossRef]

64. Johar, N.; Ahmad, I.; Dufresne, A. Extraction, preparation and characterization of cellulose fibres and nanocrystals from rice husk. Ind. Crops Prod. 2012, 37, 93-99. [CrossRef]

65. Morán, J.I.; Alvarez, V.A.; Cyras, V.P.; Vázquez, A. Extraction of cellulose and preparation of nanocellulose from sisal fibers Cellulose 2008, 15, 149-159. [CrossRef]

66. Prabhakar, M.N.; Shah, A.U.R.; Song, J.-I. A Review on the Flammability and Flame Retardant Properties of Natural Fibers and Polymer Matrix Based Composites. Compos. Res. 2015, 28, 29-39. [CrossRef]

67. Manfredi, L.B.; Rodríguez, E.S.; Wladyka-Przybylak, M.; Vázquez, A. Thermal degradation and fire resistance of unsaturated polyester, modified acrylic resins and their composites with natural fibres. Polym. Degrad. Stab. 2006, 91, 255-261. [CrossRef]

68. Poletto, M.; Zattera, A.J.; Santana, R.M.C. Structural differences between wood species: Evidence from chemical composition, FTIR spectroscopy, and thermogravimetric analysis. J. Appl. Polym. Sci. 2012, 126, E337-E344. [CrossRef]

69. Ahmetli, G.; Kocaman, S.; Ozaytekin, I.; Bozkurt, P. Epoxy Composites Based on Inexpensive Char Filler Obtained From Plastic Waste and Natural Resources. Polym. Compos. 2013, 34, 500-509. [CrossRef] 